personal exposure and hygienic characteristics of working conditions correctly.

\section{NIGHT SHIFT WORK AND EXPOSURE TO HAZARDOUS AGENTS PRESENT AT THE WORK ENVIRONMENT IN LODZ, POLAND}

B P Peplonska, Burdelak, Bukowska, Krysicka, Konieczko. Nofer Institute of Occupational Medicine, Lodz, Poland

\subsection{6/oemed-2013-101717.4}

Objectives In 2007, shift work involving circadian disruption was classified as probably carcinogenic to humans (Group 2A) by the International Agency for Research on Cancer. In most instances, the exposure in the occupational settings is complex and rarely only one hazardous occupational factor is present. Little is known so far about industrial exposures occurring in the manufacturing plants where night shift work system operates. Methods We collected data on the night shift work systems and hazardous agents present in 44 enterprises, based on a short survey filled in by the inspectors of safety and hygiene employed at the manufacturing plants. All identified hazardous factors were classified according to the IARC list of carcinogens and the European classification of carcinogens.

Results The most common system of work employs 3 (8-hour) shifts within a 5-day cycle. Altogether, as many as 153 occupational exposures occurring in the environment of the plants were identified, with noise, carbon oxide, and formaldehyde recorded among the most common exposures. Night shift work was not noted as the sole hazardous occupational factor present at the work environment in the plants. We identified 20 factors that have been evaluated by IARC, 11 of them classified to Group 1 - carcinogenic to humans. 10 factors have been classified as carcinogens according to the regulation of the European classification of carcinogens.

Conclusions Our study shows that in most instances, real life exposure circumstances at work places are complex and involve a variety of factors that may affect human response to night shift work involving circadian rhythm disruption.

The project is funded from a grant of the Polish National Research Fund, Grant No: PB5169/B/P01/2010/38.

\section{DESCRIPTIVE ANALYSIS OF THE FRENCH OCCUPATIONAL EXPOSURE DATABANKS COLCHIC AND SCOLA}

${ }^{1} \mathrm{G}$ M Mater, 'Jeandel, 'Clerc, 'Wild, 'Paris, '3avoué. 'INRS, Vandoeuvre les Nancy, France; ${ }^{2}$ Occupational Diseases Department - University Hospital of Nancy, Nancy, France; ${ }^{3}$ Department of Environmental and Occupational Health, University of Montreal, Montreal, Canada

\subsection{6/oemed-2013-101717.5}

Objectives Knowledge of historical exposures conditions in the workplace plays an important role in occupational health. Several countries have built databases of occupational hygiene measurements from prevention or compliance activities conducted over the years. The aim of this work was to describe the contents of two French databanks, COLCHIC and SCOLA, started respectively in 1987 and 2007.

Methods COLCHIC data results from prevention activities conducted by hygienists from laboratories related to governmental occupational health insurance. Its initial aims included, among others, support for epidemiological studies and implementation of prevention policies. On the other hand, SCOLA was created to store data collected in the context of mandatory verification of compliance to legal occupational exposure limits in France. Despite different objectives, COLCHIC and SCOLA share the same structure. Ancillary information includes industry, occupation, task, local and general ventilation, as well as representativeness and sampling strategies. Extracts from these two databases were obtained for the period until November 2012.

Results COLCHIC and SCOLA contain respectively 830000 and 119000 records. Data in COLCHIC cover 40 substances with more 4000 measurements, 48607 sampling visits in 24 520 factories. Data in SCOLA include 11 substances with more 1000 measurements, 33075 sampling visits in 4384 factories. The 5 most frequent substances in COLCHIC are respirable dust (62876), toluene (31766), acetone (28763), lead (24614), xylene (21768). The 5 most frequent substances in SCOLA are asbestos (63886), wood dust (12625), crystalline silicate (4353), lead (3135) and toluene (2505). The main industrial activities in both databanks are manufacturing, construction, and waste management and remediation.

Conclusions COLCHIC and SCOLA both represent important sources of information on occupational exposures. However they do not result from probabilistic sampling and their representativeness of historical exposure in France is unknown.

\section{SIGNIFICANCE OF OCTANOL-WATER PARTITION COEFFICIENT AND MOLECULAR WEIGHT AS MOLECULAR DESCRIPTORS IN PREDICTING SKIN PERMEABILITY OF CHEMICAL SUBSTANCES}

${ }^{1}$ Y C Chang, ${ }^{1,2}$ Chen. ${ }^{1}$ China Medical University, Taichung, Taiwan; ${ }^{2}$ National Kaohsiung First University of Science and Technology, Kaohsiung City, Taiwan

\subsection{6/oemed-2013-101717.6}

Objectives The occupational hazard of chemical absorption via dermal route was frequently assessed by evaluating the skin permeability $(\mathrm{Kp})$ of chemical. In addition to in vitro testing using human skin, the quantitative structure-activity relationship (QSAR) has been employed as an alternative source to providing Kp. In the early Kp QSARs the octanol-water partition coefficient $\left(\log \mathrm{K}_{\mathrm{OW}}\right)$ and molecular weight $(\mathrm{MW})$ were commonly applied as dominant properties to describe transdermal transport of chemical. This study examined the efficacy of log $\mathrm{K}_{\mathrm{OW}} / \mathrm{MW}-$ based QSARs in Kp prediction.

Methods One hundred and fifty-eight chemicals of known Kp determined in vitro using human skin were used to evaluate the goodness of fit $\left(\mathrm{R}^{2}\right)$ of the model estimates approximating the measured Kp for six log $\mathrm{K}_{\mathrm{OW}} / \mathrm{MW}$-based Kp QSARs reported in Wilschut et al. (1995) and Mitragotri (2002). A new Kp QSAR consisting of additional descriptors for the same compounds was developed by identification of key descriptors from a pool of 3,224 descriptors supported by Dragon ${ }^{\circledR}$ followed by stepwise regression. Results For the log $\mathrm{K}_{\mathrm{OW}}-\mathrm{MW}$-based Kp QSARs, the regression of model estimates against experimentally determined $\mathrm{Kp}$ yielded $\mathrm{R}^{2}$ of 0.314 to 0.744 , with the lowest value observed for the model employing $\log \mathrm{K}_{\mathrm{OW}}$ alone. In the new QSAR, in addition to $\log \mathrm{K}_{\mathrm{OW}}$ the electrostatic distribution in the molecular space appeared to be a significant factor affecting Kp, while the MW exerted its influence as a sub-domain, thus under constraints, of antineoplastic properties.

Conclusions As the Kp QSAR continues to evolve, attention may be required of on interpreting the limitations of $\mathrm{MW}$ as a 